\title{
DIRETRIZES E PRÁTICAS DE GESTÃO SOCIOAMBIENTAL NO CAMPUS DA UNIFEBE: UMA PESQUISA NO CURSO DE ADMINISTRAÇÃO
}

\author{
Denize Minatti Ferreira ${ }^{1}$ \\ Alexandre Meira Vasconcelos ${ }^{1}$ \\ George Wilson Aiub² \\ Alvaro Lezana ${ }^{1}$
}

Resumo: O objetivo do trabalho foi avaliar as diretrizes e práticas socioambientais implantadas na Unifebe. O resultado poderá subsidiar a elaboração de projetos e práticas docente e discente, bem como novas políticas institucionais para o meio ambiente. Um questionário foi aplicado com docentes e discentes da instituição, e foram analisados parâmetros pela teoria clássica dos testes (índice de facilidade, índice de discriminação, média e desvio padrão das respostas positivas do teste e intervalo de confiança para a média do total dos escores). Os resultados apontam a necessidade de a Unifebe criar uma política institucional clara, formalmente estabelecida, divulgada e implantada em todas as instâncias, pois diretrizes e políticas amplas que definam e determinem objetivos e metas devem preceder as práticas antes de serem aplicadas na instituição.

Palavras-chave: Gestão Socioambiental; Docente; Discente; Unifebe; Política Institucional Socioambiental.

${ }^{1}$ Universidade Federal de Santa Catarina. E-mails: dminatti@terra.com.br, meira1970@gmail.com, alvaro.lezana@ufsc.br.

${ }^{2}$ Centro Universitário de Brusque (Unifebe). E-mail: georgeaiub@unifebe.edu.br

Revbea, São Paulo, V. 9, N 1:56-69, 2014. 


\section{Introdução}

$\mathrm{Na}$ década de 1970, percebeu-se que o modelo de desenvolvimento vigente não era sustentável, a partir de então, disseminaram-se atitudes ecologicamente corretas. $O$ que se procura atualmente é conciliar 0 desenvolvimento econômico e social com preservação ambiental. Surge assim o que alicerça a premissa do desenvolvimento sustentável: o uso sem a exaustão dos recursos naturais. Dessa forma constrói-se o conceito de desenvolvimento sustentável: atender às necessidades da geração atual sem comprometer o direito das futuras gerações atenderem suas próprias necessidades, desse modo assegurando-lhes recursos econômicos, sociais e ambientais indispensáveis (VALLE, 2009).

O planeta pode não suportar as perdas ambientais causadas pela ação humana e comprometer o futuro da humanidade, o que coloca a questão ambiental em relevância na pauta de decisões de todos os países (SICHE et al., 2007).

Os problemas sociais, econômicos e ambientais gerados pelas diferentes atividades industriais são decorrentes da falta de visão de gestão compartilhada, ou seja, que perpasse por todas essas dimensões. Tais problemas são também frutos da relação com a natureza, que envolve não só as questões citadas, mas ainda questões éticas e visão paradigmática (BARRAQUÉ, 1995, p.9).

O desenvolvimento e a manutenção da espécie humana estão ligados à questão ambiental, e o ser humano percebe sinais de que há necessidade de se efetivarem medidas de preservação ambiental, assim a conscientização ecológica emerge a partir do diagnóstico de uma realidade que ameaça a vida e a preservação da mesma. Porém, os problemas ambientais, por sua complexidade, devem ser solucionados por indivíduos treinados e educados com pensamento crítico e que saibam transpor as fronteiras disciplinares e políticas (CUSICK et al., 2010).

Estabelecer nos indivíduos um processo de tomada de consciência ressalta a necessidade de elaborar saberes ambientais, que articulem de forma eficiente a relação interdisciplinar existente entre os setores sociais e a natureza, de forma a tornar o indivíduo mais receptivo e proativo em relação aos temas do ambiente Dessa maneira, difundir conhecimentos sobre questões ambientais é de fundamental importância considerando-se as mudanças e encaixes que as organizações estão executando tanto em sua cultura quanto em sua estrutura (TEIXEIRA et al., 2012).

Assim, medidas e procedimentos definidos e adequadamente aplicados visam a reduzir e a controlar os impactos provocados por um empreendimento no meio ambiente (ROBLES-JÚNIOR; BONELLI, 2006). Argumenta-se ser necessário um trabalho de cunho social e ambiental, com compartilhamento de objetivos e valores e uma perspectiva de trabalho que vislumbre 0 comprometimento com as gerações futuras (SACHS, 2009). Destaca-se o 
esforço das Organizações das Nações Unidas em convocar os países para uma empreitada conjunta: colocar a questão ambiental na pauta de desenvolvimento em igualdade de importância com os pilares econômicos e sociais, uma vez que o problema envolve todos - poder público, empresas e cidadãos (EWEJE, 2006).

As universidades assumem papel relevante no propósito humano por um meio ambiente saudável, pois são um espaço de reflexão para formar a geração de pensadores, trabalhadores e empreendedores que assumirão as rédeas do modelo de desenvolvimento ora estabelecido. Nessa perspectiva, este estudo foi conduzido na Unifebe (Centro Universitário de Brusque) e teve o intuito de evidenciar as práticas de gestão socioambiental docentes, discentes e da instituição e, com isso, subsidiar a instituição com informações para tomada de ações.

\section{Revisão bibliográfica}

\section{Ensino e meio ambiente: Educação Ambiental}

A questão ambiental tem sido foco em diversas áreas de conhecimento, para Teixeira et al. (2012) a necessidade de se estabelecer consciência ambiental vem influenciado os mais diferentes setores da sociedade, e a educação, como elemento principal, não poderia ficar de fora.

Os autores ainda comentam que o atual contexto ambiental leva a diversos questionamentos em busca de sentido e de explicação para a ocorrência de tamanho descaso com o meio ambiente e degradação. Dentre as diversas propostas de solução para os problemas ambientais, tais como programas de educação ambiental, certificações ambientais, legislação ambiental mais abrangente, entre outras, surge um ponto: a necessidade de desenvolvimento de consciência ambiental nos indivíduos.

Educação ambiental é o processo em que se busca despertar a preocupação individual e coletiva para a questão ambiental. Educar para o ambiente é garantir acesso à informação em linguagem adequada, a fim de contribuir para o desenvolvimento de uma consciência crítica e estimular o enfrentamento das questões ambientais e sociais. Desenvolve-se num contexto de complexidade, procura-se trabalhar não apenas a mudança cultural, mas também a transformação social. A crise ambiental é vista como uma questão ética e política (MOUSINHO, 2003).

A Lei no. 6.938/1981 rege as questões referentes e problemáticas relacionadas ao meio ambiente e às formas que nele vivem e se interrelacionam, numa perspectiva ambiental. É o parágrafo primeiro do Artigo 225 da Constituição Federal, que referencia: tornar efetivo o direito ao meio ambiente ecologicamente equilibrado e responsabiliza o Poder Público (e somente ele) por sete incumbências, mesmo impondo ao governo e à coletividade a obrigação por sua defesa e preservação. São elas: 
I - preservar e restaurar os processos ecológicos essenciais e prover o manejo ecológico das espécies e ecossistemas;

II - preservar a diversidade e a integridade do patrimônio genético do País e fiscalizar as entidades dedicadas à pesquisa e manipulação de material genético;

III - definir, em todas as unidades da Federação, espaços territoriais e seus componentes a serem especialmente protegidos, sendo a alteração e a supressão permitidas somente através de lei, vedada qualquer utilização que comprometa a integridade dos atributos que justifiquem sua proteção;

IV - exigir, na forma da lei, para instalação de obra ou atividade potencialmente causadora de significativa degradação do meio ambiente, estudo prévio de impacto ambiental, a que se dará publicidade;

V - controlar a produção, a comercialização e o emprego de técnicas, métodos e substâncias que comportem risco para a vida, a qualidade de vida e o meio ambiente;

VI - promover a educação ambiental em todos os níveis de ensino e a conscientização pública para a preservação do meio ambiente; (grifo dos autores)

VII - proteger a fauna e a flora, vedadas, na forma da lei, as práticas que coloquem em risco sua função ecológica, provoquem a extinção de espécies ou submetam os animais à crueldade.

Ainda, tem-se registrado que a educação ambiental para uma sustentabilidade equitativa é um processo de aprendizagem permanente, baseado no respeito a todas as formas de vida (TRATADO DE EDUCAÇÃO AMBIENTAL PARA SOCIEDADES SUSTENTÁVEIS E RESPONSABILIDADE GLOBAL, 2008). Essa afirmação contém que valores e ações contribuintes para a transformação humana e social e para a preservação ecológica estendem-se em todos os níveis de ensino.

Diversos trabalhos com temática ambiental, incluindo diferentes níveis de ensino têm sido publicados. Portela, Braga e Ameno (2010) investigaram as percepções de meio ambiente e educação ambiental de professores de ensino médio. Realizaram análise qualitativa de 25 entrevistas semiestruturadas em cinco escolas estaduais de Minas Gerais. Os resultados revelaram predomínio da orientação conservadora na percepção docente quanto à educação ambiental, apontando para a necessidade de se ampliar o diagnóstico e a necessidade da proposição de políticas efetivas e eficazes que possam provocar reorientação identificada com a ótica transformadora, sob pena de não se reverter o quadro de crise ambiental (e de paradigmas) perceptível na contemporaneidade. Guedes e Victorino (2010) propõem, em sua pesquisa, desenvolver práticas sociais dentro de um trabalho interdisciplinar e discutir a sustentabilidade nos cursos de formação de educadores, sobremaneira, no curso de graduação em Pedagogia. Silva (2011) relata em seu trabalho, as atividades e preocupações da UFPR Litoral, que procura trabalhar no sentido 
de contribuir para a construção de um novo modelo de universidade através da (re)invenção de espaços educativos que rompam com a concepção tradicional de conhecimento e com a relação dissociada de homem-sociedade-natureza.

Enfim, as instituições de ensino em todos os níveis têm um papel importante no desenvolvimento sustentável. Assim, ultrapassam o limite do ensino acadêmico e da formação dos alunos, e ocupam o papel social de capacitar pessoas conscientes da necessidade de garantir a sustentabilidade às gerações futuras (TAUCHEN, 2007).

\section{Gestão socioambiental}

Nos últimos anos, as organizações têm sofrido pressões de todas as ordens; a concorrência cada vez mais acirrada, as margens de lucro diminuindo, o nível de exigência de clientes aumentando e, dependendo da organização, o acesso a tecnologias de ponta está se tornando oneroso. As normais legais estão mais restritivas, e mesmo os países menos preocupados com as questões socioambientais são pressionados a implantar leis que obriguem as organizações a se tornarem ambientalmente corretas (NASCIMENTO; LEMOS; MELO, 2008).

Para os autores, a gestão socioambiental pode ser utilizada para identificar e analisar as causas da poluição, os danos causados e as formas de remediação, bem como os impactos sociais do dano ambiental, e gerar planos de ação que abordem esses temas de forma integrada. A gestão socioambiental de uma organização pode ser desenvolvida com caráter filantrópico ou como um objetivo estratégico. É, portanto, um caminho para a organização que decidir assumir responsabilidade social e adotar melhores práticas a fim de tornar seu espaço, o mais sustentável possível, contribuindo para o desenvolvimento sustentável global.

Esse caminho já começou a ser trilhado, nota-se que o papel das organizações está mudando, ainda que lentamente, mas com rumo definido para maior responsabilidade social e ambiental, inserindo-se como mais um agente de transformação e de desenvolvimento nas comunidades; participando ativamente dos processos sociais e ecológicos que estão no seu entorno e procurando obter legitimidade social pelo exemplo e não mais unicamente pela capacidade de produzir (DIAS, 2008).

No Brasil existe atualmente um movimento empresarial relacionado à crescente preocupação com as questões sociais e ambientais, e com a adoção de posturas éticas em suas atividades. Um número considerável de empresas vem investindo espontaneamente recursos no desenvolvimento social de seus empregados e das comunidades. Além disso, constata-se um significativo aumento de eventos relacionados ao tema e de entidades e associações atuantes na promoção e

divulgação da responsabilidade social das empresas.


Entretanto, não há consenso sobre o significado da responsabilidade social e as implicações para a gestão das organizações com relação à inclusão no dia-a-dia das empresas. O tema apresenta controvérsias conceituais e operacionais (VILELA-JÚNIOR; DEMAJOROVIC, 2006, p.14).

Segundo Vassalo (2000), o principal entrave para a implementação de medidas de gestão socioambientais é o desafio operacional; uma organização responsável pensa nas consequências que cada uma de suas ações pode causar ao meio ambiente, aos empregados, à comunidade, ao consumidor, aos fornecedores e a seus acionistas. Não adianta investir milhões em um projeto comunitário e, poluir os rios próximos de suas fábricas, ou ainda oferecer benefícios e oportunidades a seus funcionários e não ser transparente com seus consumidores, bem como preservar florestas e comprar componentes de fabricantes que exploram mão de obra infantil.

\section{Método de pesquisa}

A pesquisa possui abordagem quantitativa e qualitativa e se constitui da aplicação de uma survey com docentes e discentes do curso de Administração da do Centro Universitário de Brusque (Unifebe) para evidenciar as práticas de cunho socioambiental, por parte deles e da instituição.

A Unifebe, onde se aplicou a pesquisa, é uma Instituição de Ensino Superior, de caráter comunitário, mantida pela Febe (Fundação Educacional de Brusque), que administra os recursos financeiros da Unifebe. A Febe (Fundação Educacional de Brusque) é uma instituição pública de direito privado, criada pela Lei Municipal no 527, de 15 de janeiro de 1973. A administração e coordenação das atividades da Unifebe são exercidas através de órgãos da mantenedora, Febe (Fundação Educacional de Brusque), e da mantida, Unifebe (Centro Universitário de Brusque). Atualmente conta com 16 cursos de graduação com habilitações de bacharelado, tecnólogo e licenciatura. Oferece também diversos cursos de pós-graduação e extensão.

A população estudada corresponde ao universo de 50 professores e 411 estudantes do curso superior de Administração de Empresas. A proposta inicial deste artigo foi a de realizar um estudo censitário, porém selecionaramse aleatoriamente 25 professores e 30 estudantes e sucessivos testes estatísticos foram conduzidos para inferir resultados para as populações.

Os alunos foram selecionados aleatoriamente para a pesquisa, a partir de lista completa fornecida pela instituição dos alunos matriculados no curso, estratificada pelo número de alunos em cada turma, conforme quadro 1. 
Quadro 1: Estratificação dos alunos.

\begin{tabular}{|c|c|c|c|}
\hline Turma & $\begin{array}{c}\text { No alunos } \\
/ \\
\text { Turma }\end{array}$ & $\%$ & $\begin{array}{c}\text { No alunos } \\
\text { na amostra }\end{array}$ \\
\hline A01 & 36 & $9 \%$ & 3 \\
\hline A01B & 28 & $7 \%$ & 2 \\
\hline A02 & 15 & $4 \%$ & 1 \\
\hline A03 & 32 & $8 \%$ & 2 \\
\hline A03B & 26 & $6 \%$ & 2 \\
\hline A04 & 18 & $4 \%$ & 1 \\
\hline A05 & 36 & $9 \%$ & 3 \\
\hline A05B & 28 & $7 \%$ & 2 \\
\hline A06 & 33 & $8 \%$ & 2 \\
\hline A07 & 64 & $16 \%$ & 5 \\
\hline A08 & 60 & $15 \%$ & 4 \\
\hline AD01 & 18 & $4 \%$ & 1 \\
\hline AD03 & 7 & $2 \%$ & 1 \\
\hline AD07 & 10 & $2 \%$ & 1 \\
\hline TOTAL & 411 & $100 \%$ & 30 \\
\hline
\end{tabular}

Fonte: Autores.

O estrato também pôde ser mais detalhado (Quadro 2) com a divisão por gênero e por situação acadêmica. Estes alunos são oriundos de dois turnos (manhã e noite), regularmente matriculados, frequentadores do ambiente do campus e em condições de avaliar os itens propostos no questionário.

Quadro 2: Dados demográficos da amostra de alunos.

\begin{tabular}{|l|l|l|l|}
\hline \multicolumn{1}{|c|}{ Situação acadêmica } & \multicolumn{1}{c|}{$\begin{array}{c}\text { Sexo } \\
\text { Feminino }\end{array}$} & $\begin{array}{c}\text { Sexo } \\
\text { Masculino }\end{array}$ & \multicolumn{1}{|c|}{$\begin{array}{c}\text { Total } \\
\text { geral }\end{array}$} \\
\hline $\begin{array}{l}\text { Cursou mais da metade do tempo de conclusão do } \\
\text { curso }\end{array}$ & 11 & 6 & 17 \\
\hline $\begin{array}{l}\text { Cursou menos da metade do tempo de conclusão do } \\
\text { curso }\end{array}$ & 7 & 4 & 11 \\
\hline Em branco / não respondeu & 1 & 1 & 2 \\
\hline Total geral & 19 & 11 & 30 \\
\hline
\end{tabular}

Fonte: Autores.

Para cada item foi solicitado aos respondentes que avaliassem se a prática de educação/gestão socioambiental está ou não implementada na Unifebe. Os 20 itens do questionário são apresentados na seção de resultados e são iguais para docentes e discentes. Cada resposta afirmativa gerou 0,5 pontos e cada resposta negativa (ou caso o docente não saiba responder), gerou 0,0 ponto e, ao final, as respostas geraram um escore de 0,0 a 10,0 que representa o grau de implantação de tais práticas. Optou-se por considerar o 
desconhecimento do entrevistado quanto à prática socioambiental como um aspecto com pontuação 0,0 porque entendeu-se que não saber se a prática é realizada na instituição também é um problema a ser resolvido pela Unifebe.

Como o estudo censitário não pôde ser consumado, estudos estatísticos foram conduzidos a partir dos dados para inferir conclusões sobre a população. Usou-se a Teoria Clássica dos Testes (TCT) para analisar os dados coletados e a análise dos itens baseou-se nos seguintes parâmetros (VENDRAMINI; SILVA; CANALE, 2004):

a) Índice de facilidade - proporção de participantes que responderam positivamente ao item, ou seja, afirmam que a prática descrita no item é realizada na Unifebe. Considera-se um item como "fácil" quando o índice é maior que 0,70 e difícil quando é menor ou igual a 0,30. Índices de facilidade altos indicam que a prática existe e é reconhecida pela comunidade universitária.

b) Índice de discriminação - que mede a capacidade do item de diferenciar os participantes que afirmam que a prática descrita no item é executada na Unifebe ( $27 \%$ dos respondentes com escores mais altos) daqueles que afirmam que a prática não é executada, ou não sabem dizer se é executada ( $27 \%$ dos respondentes com pontuações mais baixas) e corresponde à diferença entre a proporção de respostas positivas do primeiro grupo e a do segundo grupo;

c) Alfa de Cronbach - para verificar a confiabilidade do teste e é considerado alto para valores superiores a 0,60. Trata-se de estimar a precisão do teste, ou seja, se os itens covariam numa ocasião, espera-se que ocorra o mesmo toda vez que o teste for aplicado (PASQUALI, 2009). Calcula-se o valor a pela fórmula (HORA; REGO-MONTEIRO; ARICA, 2010):

$$
\alpha=\left(\frac{k}{k-1}\right) \times\left(1-\frac{\sum_{i=1}^{k} s_{i}^{2}}{s_{t}^{2}}\right)
$$

k é o número de itens do questionário;

$\boldsymbol{s}_{i}^{2}$ é a variância de cada item;

$S_{t}^{2}$ é a variância total do questionário, calculada pela soma de todas as variâncias.

d) A média e o desvio-padrão do número total de respostas positivas;

e) A média do total dos escores - Uma vez que o estudo não foi censitário, será conduzido um teste de significância para inferir a média da população para um nível de confiança de 95\%. Um teste de hipótese será conduzido para evidenciar discrepâncias entre as médias obtidas nos questionários dos docentes e dos discentes:

$\mathbf{H}_{0}$ : não há discrepância entre as médias dos escores dos docentes e discentes

$\mathbf{H}_{1}$ : as médias dos escores dos docentes e discentes são diferentes. 


\section{Análise e discussão dos resultados}

O Quadro 3 apresenta os dados coletados no período de 30 de maio a 04 de julho de 2012. Todos os professores (16 homens e 9 mulheres) têm um ano ou mais de atuação profissional na Unifebe, o que lhes confere um tempo de experiência suficiente para analisarem a situação da instituição quanto às práticas socioambientais.

Constata-se que as diretrizes organizacionais obtiveram a média mais baixa e maior dispersão, o que sugere que precisam ser instituídas, reavaliadas ou implantadas, conforme cada caso. Os itens 01,11 e 17 são "fáceis" tanto para docentes quanto discentes, o que evidencia que estão implementadas e são reconhecidas pela maioria da comunidade universitária. O mesmo não acontece com os demais itens $(05,12,14$ e 16) que precisam da atenção especial da organização. Em relação ao índice de facilidade, entre os mais "difíceis" (12, 14, 16 e 19) há três que apontaram diretrizes e políticas não institucionalizadas e os mais "fáceis" $(02,06,08,10,11,13,14$ e 20) são relacionados à prática. A constatação sugere que a Unifebe deve criar uma política institucional clara. As políticas e diretrizes socioambientais devem ser claras, formalizadas em um programa específico e disseminadas por toda a organização, em todos os níveis, por pessoas designadas especialmente para tal. Portanto, ao desenvolver atividades orientadas para a prática sustentável é fundamental que se tenha o compromisso e a participação de todos os envolvidos. No entanto, essa participação pode ser facilitada através das ações de um programa formal de educação ambiental que atue de forma contínua, de maneira a apoiar a execução das atividades envolvidas no processo de gestão ambiental, bem como, a despertar a participação consciente dos sujeitos envolvidos no processo (TEIXEIRA et al., 2012).

Quanto às práticas institucionais vistas pelos docentes, o número mais baixo de respostas positivas foi nove para o item 09, e o item mais pontuado foi o número 02 , com 17 respostas positivas, sobre a existência de iniciativas de responsabilidade socioambiental. As respostas dos alunos chegaram a mesma conclusão. O número elevado de respostas positivas neste grupo, e a pouca variabilidade dos resultados, indica que há percepção da comunidade universitária de que a instituição se mobiliza para realizar ações socioambientais.

Quanto às práticas socioambientais de docentes e demais colaboradores, destaca-se o item 19, com somente três respostas positivas, ou seja, os docentes desconhecem ou têm conhecimento de que os professores não se utilizam da gestão ambiental de forma transversal em suas disciplinas, o que pode orientar ações da coordenação de curso e/ou coordenação pedagógica para a revisão de planos de ensino para contemplar esse item. 0 mesmo resultado foi observado na dedução dos discentes. Neste grupo de questões, ainda se destaca o item 10, como o mais bem pontuado, com respostas positivas sobre a promoção pela Unifebe de ações educativas para alunos e colaboradores. Embora se saiba que não há referências pedagógicas 
Quadro 3: Parâmetros dos itens da survey aplicada aos docentes e discentes.

\begin{tabular}{|c|c|c|c|c|c|c|}
\hline \multirow[b]{2}{*}{ ITEM DO QUESTIONÁRIO } & \multicolumn{3}{|c|}{ DOCENTES } & \multicolumn{3}{|c|}{ DISCENTES } \\
\hline & $\begin{array}{l}\Sigma \\
\text { क } \\
\circ\end{array}$ & 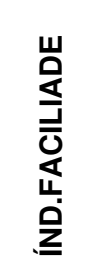 & 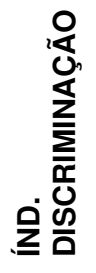 & $\begin{array}{l}\sum \\
\text { क } \\
\circ\end{array}$ & 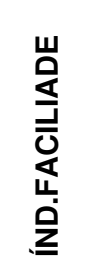 & 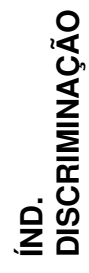 \\
\hline \multicolumn{7}{|l|}{ DIRETRIZES ORGANIZACIONAIS } \\
\hline $\begin{array}{l}\text { 1. A Unifebe demonstra elevado grau de comprometimento com } \\
\text { questões relacionadas a meio ambiente e com o bem estar da } \\
\text { sociedade. }\end{array}$ & $65 \%$ & 0,72 & 0,60 & $83 \%$ & 0,86 & 0,20 \\
\hline 5. A Unifebe incentiva o uso racional de energia elétrica. & $60 \%$ & 0,67 & 0,20 & $30 \%$ & 0,30 & 0,40 \\
\hline $\begin{array}{l}\text { 11. A Unifebe estimula a participação dos funcionários } \\
\text { (professores e técnicos) em ações que beneficiam a comunidade. }\end{array}$ & $80 \%$ & 0,89 & 0,20 & $77 \%$ & 0,77 & $-0,40$ \\
\hline 12. A Unifebe tem uma política socioambiental institucionalizada & $10 \%$ & 0,11 & 0,40 & $27 \%$ & 0,30 & 0,00 \\
\hline 14. Existem políticas de gestão de resíduos na Unifebe. & $25 \%$ & 0,28 & 0,80 & $33 \%$ & 0,34 & $-0,40$ \\
\hline $\begin{array}{l}\text { 16. A Unifebe dispõe de pessoal especializado em questões } \\
\text { socioambientais e as decisões são tomadas por meio de comitê } \\
\text { responsável. }\end{array}$ & $20 \%$ & 0,22 & 0,40 & $20 \%$ & 0,20 & $-0,20$ \\
\hline $\begin{array}{l}\text { 17. A Unifebe incentiva os funcionários/alunos a participarem das } \\
\text { questões socioambientais. }\end{array}$ & $60 \%$ & 0,67 & 0,60 & $63 \%$ & 0,66 & 0,00 \\
\hline \multicolumn{7}{|l|}{ PRÁTICAS INSTITUCIONAIS } \\
\hline $\begin{array}{l}\text { 2. Existem iniciativas de educação para a responsabilidade } \\
\text { socioambiental na Unifebe. }\end{array}$ & $85 \%$ & 0,94 & 0,00 & $77 \%$ & 0,77 & $-0,20$ \\
\hline 3. Faz-se coleta seletiva de lixo na Unifebe. & $65 \%$ & 0,72 & 0,20 & $60 \%$ & 0,64 & 0,60 \\
\hline $\begin{array}{l}\text { 7. Na Unifebe, as ações da gestão universitária seguem } \\
\text { princípios do desenvolvimento sustentável. }\end{array}$ & $50 \%$ & 0,56 & 1,00 & $67 \%$ & 0,67 & $-0,80$ \\
\hline $\begin{array}{l}\text { 8. Existem campanhas de conscientização para cuidados com o } \\
\text { meio-ambiente na Unifebe. }\end{array}$ & $65 \%$ & 0,72 & 0,80 & $90 \%$ & 0,90 & 0,00 \\
\hline $\begin{array}{l}\text { 9. A Unifebe se preocupa em utilizar e fornecer materiais } \\
\text { pensando na disposição final destes, ou seu impacto no meio } \\
\text { ambiente. }\end{array}$ & $45 \%$ & 0,50 & 0,40 & $33 \%$ & 0,33 & $-0,40$ \\
\hline 13. Há respeito e valorização dos funcionários na Unifebe. & $70 \%$ & 0,78 & 0,40 & $67 \%$ & 0,67 & $-0,60$ \\
\hline 18. A atividade econômica da Unifebe interfere no meio ambiente. & $50 \%$ & 0,56 & $-0,40$ & $47 \%$ & 0,47 & $-0,20$ \\
\hline \multicolumn{7}{|l|}{ PRÁTICAS DOCENTES } \\
\hline $\begin{array}{l}\text { 4. Os funcionários e alunos da Unifebe colaboram com a Gestão } \\
\text { Socioambiental (ex. desperdício de papel, não discriminação de } \\
\text { pessoas, economia de água e luz,). }\end{array}$ & $45 \%$ & 0,50 & 1,00 & $53 \%$ & 0,55 & $-0,20$ \\
\hline $\begin{array}{l}\text { 6. Na Unifebe se reaproveita folhas de papel ou se utiliza papel } \\
\text { reciclado para fins de impressão. }\end{array}$ & $70 \%$ & 0,78 & 0,00 & $27 \%$ & 0,27 & $-0,20$ \\
\hline $\begin{array}{l}\text { 10. A Unifebe promove ações educativas para a formação da } \\
\text { cidadania dos colaboradores e dos alunos. }\end{array}$ & $75 \%$ & 0,83 & 0,00 & $73 \%$ & 0,76 & 0,20 \\
\hline $\begin{array}{l}\text { 15. Há coerência entre discurso e prática na Unifebe quando se } \\
\text { trata de questões de Gestão Socioambiental. }\end{array}$ & $45 \%$ & 0,50 & 1,00 & $57 \%$ & 0,57 & $-0,40$ \\
\hline $\begin{array}{l}\text { 19. Todos os professores abordam a questão ambiental em suas } \\
\text { disciplinas. }\end{array}$ & $15 \%$ & 0,17 & 0,40 & $17 \%$ & 0,17 & 0,20 \\
\hline $\begin{array}{l}\text { 20. Há projetos de pesquisa/iniciação científica que contemplam } \\
\text { a Gestão Socioambiental. }\end{array}$ & $50 \%$ & 0,56 & 0,80 & $50 \%$ & 0,52 & $-0,60$ \\
\hline
\end{tabular}

Fonte: Autores.

Revbea, São Paulo, V. 9, Nº 1: 56-69, 2014. 
conceituais e teóricas suficientes para dar suporte à prática docente (MORADILLO; MOKI, 2004), os saberes sobre o meio ambiente podem ser construídos no espaço da universidade com práticas que considerem sua multidimensionalidade, que sejam inclusivas, valorizem os aspectos subjetivos, as diferentes culturas, sempre com o intuito de o aluno se apropriar desse conhecimento de forma emancipatória (TRISTÃO, 2005), com corresponsabilidade e ética em práticas profissionais (JACOBI, 2005).

O índice de discriminação demonstra que os itens 04,07 e 15 discriminam totalmente as pessoas que têm uma visão positiva sobre as práticas docentes daqueles que não têm, enquanto os itens $02,03,05,06,10$, 11 e 18 são os que menos discriminam, ou seja, índices de discriminação altos indicam que as práticas são reconhecidas somente por parte da comunidade universitária, o que pode evidenciar um problema de comunicação sobre as ações socioambientais no ambiente interno da instituição, ou que se tratar de informações divulgadas somente a grupos privilegiados.

Os escores médios das respostas dos docentes e discentes são mostrados no Quadro 4. Mostra-se também o intervalo de confiança, calculado pelo teste $t$ de Student bicaudal, com um nível de confiança de 95\%, considerando os graus de liberdade, e a população finita de docentes e discentes. O escore médio relacionado a esta avaliação - próximo da metade do valor máximo do teste - pode ser usado para estabelecer metas de desempenho socioambiental, tanto para docentes quanto para discentes.

Quadro 1: Resultados da análise estatística dos dados pela teoria clássica.

\begin{tabular}{|l|c|c|}
\hline \multicolumn{1}{|c|}{ Resultados } & DOCENTE & DISCENTE \\
\hline População & 50 & 411 \\
\hline Amostra & 25 & 30 \\
\hline Graus de liberdade & 17 & 29 \\
\hline Média do escore & 5,53 & 5,25 \\
\hline Desvio padrão & 2,18 & 1,83 \\
\hline Intervalo de confiança (95\%) & $(4,65 ; 6,40)$ & $(4,59 ; 6,10)$ \\
\hline Alfa de Cronbach & 0,83 & 0,73 \\
\hline
\end{tabular}

Fonte: Autores.

Como a priori, a variância das populações de alunos e professores é desconhecida, em primeiro lugar será avaliado se o tamanho das amostras foi suficiente. Usa-se o desvio-padrão $\left(S_{0}\right)$ de cada grupo como uma estimativa inicial para desvio-padrão da população $(\sigma)$ e calcula-se o tamanho $n$ ideal da amostra com n-1 graus de liberdade para teste bilateral pela distribuição $t$, supondo se tratar de uma distribuição normal (BARBETTA; REIS; BORNIA, 2010). Cada amostra será completada com n- $n_{0}$ observações, caso a amostra- 
piloto seja inferior ao valor ideal $\mathrm{n}$. Para um erro máximo arbitrado de 1,0 ponto entre o escore estimado $\left(\mu_{0}\right)$ e o da população $(\mu)$, um nível de significância $(\alpha)$ de $5 \%$, o tamanho mínimo para a amostra, será o estabelecido na equação 2 . Os cálculos resultados em um valor $n=21$ para os docentes, $n=14$ para os discentes, o que indicam que as amostras-piloto foram suficientes para a análise.

$$
n \geq \frac{t_{\alpha / 2}^{2} s_{0}^{2}}{\left|\mu-\mu_{0}\right|^{2}}
$$

Teste $t$ para amostras independentes, de tamanhos diferentes (BARBETTA; REIS; BORNIA, 2010) foi realizado para testar a hipótese de pesquisa, ou seja, para verificar se há ou não discrepância nas médias de docentes e discentes. O cálculo resultou em uma estatística do teste com valor $t=0,35$. Como valor crítico $t_{c}=2,013$ para $\alpha=0,05$ e 46 graus de liberdade $\left(n_{1}+\right.$ $n_{2}-2$ ), entende-se que o valor $t=0,35$ pertence à região de aceitação, e se conclui pela aceitação da hipótese nula $\left(\mathrm{H}_{0}\right)$, ou seja, afirma-se com $95 \%$ de confiança que os escores dos docentes e discentes têm a mesma média. Os valores médios podem ser utilizados como um indicador de implantação de práticas educativas socioambientais para a Unifebe e metas podem ser estabelecidas e sua implantação verificada com o auxílio do instrumento. $O$ teste mostrou-se consistente por meio do alfa de Cronbach elevado para os docentes e discentes.

\section{Conclusões}

Os resultados demonstram que alunos e professores do curso de Administração têm a mesma média para os escores do teste. Em face dos resultados, a Unifebe precisa rever suas diretrizes e práticas de gestão socioambiental, com especial destaque para a formalização e disseminação de um programa de gestão de responsabilidade socioambiental, para que a defesa do meio ambiente e a responsabilidade social não estejam concentradas em práticas isoladas e desconexas. Porém, como este estudo foi exploratório em um único curso, sugere-se que seja ampliado para toda a Unifebe, com a participação dos docentes e demais colaboradores, bem como da diretoria para evidenciar visão mais ampla da situação e verificar se os resultados aqui apresentados podem ser generalizados para toda a organização.

A política institucional socioambiental deverá ser utilizada para direcionar as ações do centro universitário em todos os níveis, com especial atenção para a atividade docente e discente, com vistas à inclusão desta temática em todas as disciplinas de todos os cursos. Sabe-se que há esforços para que a temática socioambiental se transforme em disciplina institucional e seja oferecida em todos os cursos da Unifebe, mas essa ação deve ser priorizada. 


\section{REFERÊNCIAS}

BARRAQUÉ, B. Les politiques de l'eau en Europe. Éditions La Découverte. Piaget Institut, France, 1995.

BARBETTA, P.A.; REIS, M.M.; BORNIA, A.C. Estatística para cursos de engenharia e informática. $3^{\underline{a}}$ ed. São Paulo-SP: Atlas, 2010.

BRASIL. Lei № 6938 de 31 de agosto de 1981. Disponível em:

$<$ http://www.planalto.gov.br/ccivil 03/leis/l6938compilada.htm > Acesso em: 20 ago. 2012.

CUSICK J.; MONROE C.; MACLEOD S.; BARKER N.H. Sustainability Education and Public Diplomacy: A Case Study of the United States Institute on the Environment. Environmental Practice. v. 12, n. 1, p. 8-17, 2010.

DIAS, R. Gestão ambiental: Responsabilidade Social e Sustentabilidade. São Paulo: Atlas, 2006.

EWEJE, G. Strategic partnerships between MNEs and civil society: the post-WSSD perspectives. Sustainable Development, v. 15, n. 1, p. 15-27, 2007.

GUEDES, I.C., VICTORINO, L.A. Breve discussão sobre a sustentabilidade nos cursos de formação de educadores: Construindo as Bases para uma Educação Sustentável. Rev. eletrônica Mestr. Educ. Ambient. ISSN 1517-1256, v. 24, janeiro a julho de 2010.

HORA, H.R.M.; REGO-MONTEIRO, G.T.; ARICA, J. Confiabilidade em Questionários para Qualidade: Um Estudo com o Coeficiente Alfa de Cronbach. Produto \& Produção, v. 11, n. 2, 2010.

JACOBI, P.R. Educação ambiental: o desafio da construção de um pensamento crítico, complexo e reflexivo. Educação e Pesquisa, v. 31, n. 2, p. 233-250, 2005.

MORADILLO, E.F.; MOKI, M.C. Educação ambiental na universidade: construindo possibilidades. Química Nova, v. 27, n. 2, p. 332-336, 2004.

MOUSINHO, P. Glossário. In: Trigueiro, A. (Coord.) Meio ambiente no século 21. Rio de Janeiro: Sextante. 2003

NASCIMENTO, L.F., LEMOS, A.D.C., MELLO, M.C.A. Gestão socioambiental estratégica. Porto Alegre: Bookman, 2008.

PASQUALI, L. Psicometria. Rev Esc Enferm USP, v. 43, n. Esp, p. 992-999, 2009.

PORTELA, S.T., BRAGA, F.A., AMENO, H.A. Educação ambiental: entre intenção e ação. Rev. eletrônica Mestr. Educ. Ambient. ISSN 1517-1256, v. 24, janeiro a julho de 2010.

ROBLES-JÚNIOR A.; BONELLI V. Gestão da qualidade e do meio ambiente: enfoque econômico, financeiro e patrimonial. São Paulo: Atlas; 2006. 
SACHS, I. Caminhos para o Desenvolvimento Sustentável. Rio de Janeiro: Garamond, 2009.

SICHE, R.; AGOSTINHO, F.; ORTEGA, E.; ROMEIRO, A. Índices versus indicadores: precisões conceituais na discussão da sustentabilidade de países. Ambiente \& sociedade. v. 10, p. 137-148, 2007.

SILVA, M.L. Percepção da flora por calouros do ensino superior: A importância da educação ambiental. Rev. eletrônica Mestr. Educ. Ambient. ISSN 15171256, v. 6, n. 1 (2011).

TAUCHEN, J.A. (2007). Um modelo de gestão ambiental para a implantação em instituições de ensino superior. Dissertação (Mestrado em Engenharia). Universidade de Passo Fundo/RS.

TEIXEIRA, J.C M.; QUEIROS, A.P.C.; NOGUEIRA, C M.S.; BRITO, M.L.A.; LIMA, E.R.M.; SILVA, A.M.A. O ensino de Gestão Ambiental na visão de discentes do curso de Administração. Disponível em:

$<$ http://www.revistaea.org/artigo.php?idartigo $=1158$ \&class $=02>$ Acesso em: 30 ago. 2012.

TRISTÃO, M. Tecendo os fios da educação ambiental: o subjetivo e o coletivo, o pensado e o vivido. Educação e Pesquisa, v. 31, n. 2, p. 251-264, 2005.

VALLE, C.E. Qualidade Ambiental-Iso 14.000. São Paulo: Senac; 2009.

VASSALLO, C. Um novo Modelo de Negócios. Guia de boa cidadania corporativa. Revista Exame. São Paulo - SP: n 728, p.08 - 11, 2000.

VENDRAMINI, C.M.M.; SILVA, M.C.; CANALE, M. Análise de itens de uma prova de raciocínio estatístico. Psicologia em Estudo, v. 9, n. 3, p. 487 - 498, 2004.

VILELA-JÚNIOR; D. Tratado de educação ambiental para sociedades sustentáveis e responsabilidade global. 2006. Disponível em: <http://portal.mec.gov.br/secad> Acesso em: 25 ago. 2012. 